\title{
REFLEXOS DA DESCONCENTRAÇÃO PRODUTIVA BRASILEIRA NO ESTADO DO RIO DE JANEIRO: ESTUDOS PRELIMINARES DOS IMPACTOS DA PSA PEUGEOT-CITROËN NO MUNICÍPIO DE PORTO REAL
}

\author{
Daniel Delfino Souza \\ Universidade Federal Rural do Rio de Janeiro \\ Cezar Augusto Miranda Guedes \\ EMail: danieldelfi@gmail.com
}

\section{Resumo}

O presente artigo tem por objetivo analisar os reflexos do fenômeno de desconcentração produtiva nacional no estado do Rio de Janeiro, em especial a inter-relação da economia e as transformações no município de Porto Real. Para o período 1930-2005, é apresentado um panorama das dinâmicas dos processos de concentração e desconcentração e de que modo eles afetaram a distribuição geográfica da indústria automobilística no Brasil, bem como os impactos nos principais indicadores socioeconômicos de Porto Real com a chegada da PSA Peugeot-Citroën ao município, focando-se a análise no período de 2000-2016. Ao se apontarem as principais mudanças observadas na estrutura econômica e territorial municipal, destacamse: o crescimento populacional acelerado, a queda dos investimentos públicos, a dependência de transferências de recursos e, principalmente, a defasagem dos salários. Para isso, o trabalho se apoiou em pesquisas bibliográficas e nos bancos de dados de órgãos responsáveis pelo levantamento e gerenciamento de dados estatísticos sociais, econômicos e financeiros.

Palavras-chave: Desconcentração produtiva, PSA Peugeot-Citroën, Porto Real

\begin{abstract}
The objective of this article is to analyze the effects of the phenomenon of national productive deconcentration in the state of Rio de Janeiro, especially the interrelation of the economy and the transformations in the municipality of Porto Real. For the period 1930-2005, an overview of the dynamics of concentration and deconcentration processes is presented and how they affected the geographical distribution of the automobile industry in Brazil, as well as the impacts on the main socioeconomic indicators of Porto Real with the arrival of PSA Peugeot- Citroën to the municipality, concentrating the analysis in the period from 2000 to 2016. Pointing out the main changes observed in the municipal economic and territorial structure, the following stand out: accelerated population growth, falling public investments, dependence on transfers of resources and, mainly, the wages gap. For this, the work was based on bibliographical research and on the databases of organs responsible for the collection and management of social, economic and financial statistical data.

Key words: Decontamination of production, PSA Peugeot-Citroën, Porto Real
\end{abstract}


A cultura do café tem uma grande importância para a economia brasileira. O cultivo do produto para a exportação dinamizou a economia e permitiu uma acumulação de capital, principalmente para os cafeicultores do oeste de São Paulo, o que proporcionou posteriormente a existência de um complexo econômico de base industrial. No período de 1930 a 1970, o crescimento da indústria no Estado se deu de modo desigual ao restante do país e foi impulsionado, principalmente, pelo investimento em infraestrutura urbana, alto desempenho da agricultura, mão de obra barata e os altos níveis de produtividade da indústria paulista. Com isso, a região sudeste do Brasil, em especial o estado de São Paulo, passou a concentrar a maior parte dos investimentos públicos e privados, atraindo imigrantes de todas as regiões, os quais integraram a mão de obra necessária para as indústrias em expansão e as nascentes. Esses fatores consolidaram o processo concentrador. (Cano, 1998)

Nesse contexto, até a virada do século XIX para o século XX, o estado do Rio de Janeiro tinha uma indústria em expansão e um protagonismo histórico no cenário econômico, cultural e político brasileiro. Contudo, a partir de 1907, com a crise da economia cafeeira no Vale do Paraíba, além da reversão da polarização da economia nacional para São Paulo a partir de 1920 e a transferência da capital da cidade do Rio de Janeiro para Brasília em 1960, o Estado viu sua indústria mostrar-se frágil, gerando alta dependência do setor de serviços e do setor público, bem como uma insignificante atividade agrícola, assumindo assim uma condição periférica (Sobral, 2007).

O milagre econômico vivido pelo Brasil na década de 1970 proporcionou um crescimento industrial em média de 9,3\% ao ano e uma clara desconcentração produtiva observada por meio de plantas de alguns investimentos para a periferia, graças a políticas que buscavam compensar as desigualdades regionais e o fortalecimento do mercado interno. Alguns fatores podem explicar essa desconcentração: investimentos nacionais fora do eixo Rio de Janeiro - São Paulo e que visavam às regiões menos favorecidas; a guerra fiscal que estimulou a competição entre estados e entre municípios por meio de mecanismos tributários; crise no padrão de acumulação e redução do papel do Estado na estrutura; subordinação ao processo de globalização. (Cano, 2007)

Importantes alterações ocorreram no estado do Rio de Janeiro. Ele recebeu rebatimentos da reorientação espacial dos investimentos, privilegiando certas regiões do Estado, como o Norte-Fluminense, com a indústria de extração mineral, e o Médio-Paraíba, com a indústria automobilística. Como resultado, em 2001, no município de Porto Real, foi instalada a montadora PSA Peugeot-Citroën "graças aos esforços dos governos estaduais e municipais e à influência de seus representantes políticos". (Ramalho \& Santana, $2006:$ p.117)

O município de Porto Real fica localizado ao sul do Rio de Janeiro, Estado com o segundo maior PIB do Brasil. Pertence à região do Médio-Paraíba, uma das oito Regiões de Governo de acordo com divisão político-administrativa do Estado e apresenta, como municípios limítrofes, Barra Mansa, Quatis e Resende. Segundo o Instituto Brasileiro de Geografia e Estatística (IBGE), Porto Real tem uma área territorial 50,779 $\mathrm{km}^{2}$, vigorando entre os cinco menores municípios do Estado, uma população de 17.970 habitantes e o Produto Interno Bruto de $\mathrm{R} \$ 3,1$ bilhões. Com isso, o município passou a vigorar como o terceiro maior PIB per capita do Estado e o $12^{\circ}$ maior do País. (IBGE, 2017)

Porto Real tem sua origem ligada à de Resende, município do qual foi distrito até 1997, e atrelada ao ciclo do ouro no Brasil, nos séculos XVII e XVIII. Recebeu esse nome devido a um pequeno porto construído às margens do rio Paraíba do Sul, onde o imperador D. Pedro I fazia paradas quando retornava de Petrópolis e hospedava-se em uma mansão localizada na região. Porém, a colonização começou de fato a partir de 1875, voltada ao cultivo da cana-de-açúcar por imigrantes italianos. A usina açucareira ali instalada foi o ponto de partida para uma fase industrial do então distrito. Em pouco tempo, Porto Real foi ganhando importância, até se emancipar de Resende em 1997.

O presente artigo tem por objetivo analisar os reflexos do fenômeno de desconcentração produtiva nacional no estado do Rio de Janeiro, em especial a inter-relação da economia e as transformações no município de Porto Real. Dessa forma, para o período 1930-2005, apresenta-se um panorama das dinâmicas dos processos de concentração e desconcentração produtiva nacional e como ela afetou a distribuição geográfica da indústria automobilística no Brasil, bem como os impactos nos principais indicadores socioeconômicos de Porto Real com a chegada da PSA Peugeot-Citroën ao município, concentrando a análise no período de 1999-2016. 


\section{2 “A MARCHA PARA O OESTE" DO CAFÉ: DO VALE DO PARAÍBA AO OESTE PAULISTA E A FORMAÇÃO DE UM COMPLEXO CAFEEIRO CONCENTRADO}

O café chegou ao Brasil por volta de 1727, por intermédio das expedições de Francisco de Mello Palleta à Guiana Francesa e logo passou a ser cultivado no âmbito da subsistência. Porém, a partir de 1820, o grão aparece como uma cultura de exportação graças a uma combinação de fatores conjunturais e substanciais: nas residências e nos cafés das mais importantes cidades europeias, o produto era consumido como uma especiaria; com a melhoria dos padrões de vida na Europa e na América do Norte, resultado do progresso advindo da revolução industrial, o consumo de café intensificou-se rapidamente. O crescimento da demanda dava-se enquanto esses continentes se urbanizavam e crescia o contingente populacional.

A produção para exportação ficou concentrada no Vale do Paraíba do Sul, devido a uma combinação de fatores: a) Solo, clima e topografia (abundância de terras); b) Região estratégica, pois se situa entre os estados do Rio de Janeiro, São Paulo e Minas Gerais. Além disso, existia um caminho que levava ao porto do Rio de Janeiro, caminho esse utilizado para escoar a produção de ouro; c) disponibilidade de recursos financeiros, pois naquela altura a mineração era decadente, mas essa ajudou na formação de cidades, de atividades de subsistência que foram desenvolvidas para dar apoio à atividade da mineração.

Na região do Vale do Paraíba, a atividade do café foi de monocultura para exportação, agricultura extensiva, que seguia a tradição do tripé latifundiário, escravista e monocultor, mas que utilizava técnicas muito precárias que compreendiam desde o preparo do solo pela queimada até a derrubada da Mata Atlântica. (Marco Aurélio dos Santos, 2017).

O plantio também se dava de maneira equivocada. A terra era muito acidentada, com relevo bastante declivoso, fazendo com que o plantio do café fosse feito nas encostas verticalmente. Essa técnica diminuía muito a produtividade, principalmente em períodos de chuva, que lavava o solo e retirava nutrientes. "Os vícios de estruturação não foram sanados, no decorrer do século, nem a técnica de tratar a terra, que acabou conhecendo exaustão prematura. A erosão nos morros fazia baixar a produtividade dos cafezais". (Sobrinho, 1978, p. 107)

Segundo Motta Sobrinho (1978:), a partir de 1850, a produção no Vale do Paraíba começou a enfrentar problemas e, no final do século XIX, ocorreu a decadência da produção do café nessa região, sendo então abandonada pelos produtores, que buscavam novas áreas que fossem mais férteis e gerassem mais produtividade. Os principais fatores da decadência foram a forma de cultivo rudimentar e a escassez de mão de obra devido ao fim do trabalho escravo. Por conta disso, fazendeiros passaram a ter dificuldade de honrar seus compromissos junto aos bancos, e os empréstimos para produção começaram a diminuir. A escassez de recursos financeiros feriu de morte a produção de café concentrada no Vale do Paraíba.

O café, no último quartel do século XIX, iria atravessar sua maior crise, resultante dos males de sua estrutura econômica agravados pela abolição, pelo receio de insolvência dos cafeicultores, pela concorrência de novas zonas produtoras, onde a cafeicultura fora estabelecida de modo mais racional, com o reforço do trabalho livre do imigrante europeu, italiano principalmente, e por último, pela superprodução. (Sobrinho, 1978, p. 107)

Esgotada a possibilidade de expansão do café no Vale do Paraíba, a produção para exportação saiu da região e encontrou no Oeste Paulista condições favoráveis para dar continuidade ao processo de acumulação. Pesaram fortemente, a favor do estado de São Paulo, a introdução e a expansão do sistema ferroviário, frutos de investimentos feitos pela Inglaterra na América Latina, que reduzia os custos de transporte do café até os portos para o escoamento da produção, permitindo a ampliação das fronteiras agrícolas e a exploração de terras virgens, aumentando a produtividade, pois, com a redução no tempo de transporte, reduzia-se a perda. A prova disso está nos custos que variavam de $33 \%$ (Jundiaí a Santos) até $50 \%$ (Rio Claro a Santos) do preço de exportação e caíram para $20 \%$ do preço de exportação. $($ Cano, 1998$)$ 


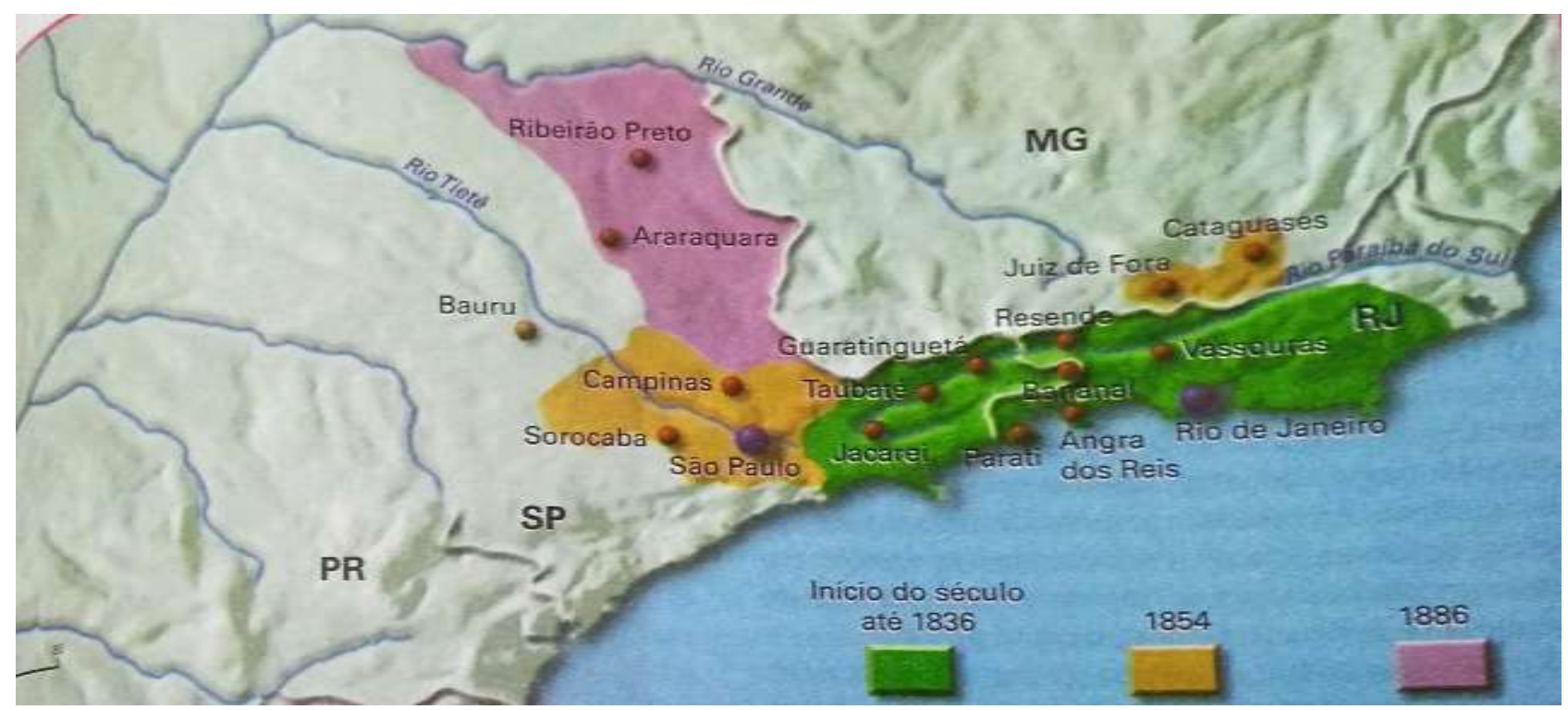

Figura 1 - Ciclo do café: expansão para o oeste paulista

Fonte: Mapa de Nigro em Nova História Crítica

Obviamente, esse não foi o único fator de decisão pela região. A expansão de sua produção pode também ser explicada pelo relevo e clima, sendo predominantemente plano, com temperaturas amenas e chuvas regularmente distribuídas ao longo do ano; a terra no oeste paulista era de qualidade superior para a produção de café; as técnicas de plantio e manuseio eram mais avançadas e adequadas; havia máquinas de beneficiamento da produção; mão de obra composta por imigrantes europeus assalariados; 0 nascimento de uma nova classe ligada à agricultura com forte influência política e econômica, conformando uma oligarquia cafeeira paulista. (Baer, 2003)

O processo de concentração passa pela formação de um complexo econômico de base cafeeira e exclusiva ao estado de São Paulo. A elevada produtividade da região' a alta demanda mundial, a diminuição dos custos de transporte, o uso intenso de máquinas e equipamentos e a expansão da força de trabalho livre e assalariada permitiram uma ampliação das taxas de lucros via mercado interno e, consequentemente, a diversificação das atividades econômicas e da produção agrícola. (Cano, 1998)

A política de defesa da renda dos cafeicultores presentes durante a crise de 1929 permitiu a manutenção dos lucros desses cafeicultores em nível elevado, o que permitiu, por conseguinte, a transferência de capital da cafeicultura para a indústria, fomentando uma nova atividade, que vai se mostrar extremamente lucrativa, provocando uma concentração econômica na região e o agravamento do desequilíbrio regional, o que significou o aumento da concentração de renda e riqueza na região do café-sudeste.

As ideias de Cano (1998) permitem concluir que a atividade industrial surgida em torno do complexo cafeeiro pôde contar com um excedente de capital que constantemente, de modo cíclico, era reinvestido no próprio setor. Dessa forma, as indústrias que foram sendo constituídas gravitaram em tomo do complexo cafeeiro, ou seja, ao redor de São Paulo. Assim, surgiu o processo de concentração industrial. A acumulação de capital, que teve como núcleo o cultivo do café, foi tomando diversas faces, promovendo uma concentração de investimentos, dentre eles no setor industrial. Forte expansão industrial que, apesar de apresentar taxas maiores em São Paulo, reforçou a concentração industrial. (Cano, 1998)

\section{DESCONCENTRAÇÃO PRODUTIVA E O RIO DE JANEIRO}

Houve um movimento, a partir da excepcional década de 1970, de elevado crescimento primário, secundário e urbano, com notável aumento da diversificação da estrutura produtiva industrial, quando se

\footnotetext{
${ }^{1}$ Entre 1901 e 1905, a produção exportável de café em São Paulo foi de 41,3 milhões de sacas por quinquênio; já entre 1926 e 1930 , a produção exportável foi de 66 milhões de sacas.
} 
caracterizou claramente o que o pesquisador chama de "desconcentração positiva ou virtuosa", dado que o crescimento da indústria de transformação de São Paulo, embora elevado (120\% na década), foi superado pelo da periferia (164\%). No período, os nexos inter-regionais fortaleceram-se, e a estrutura industrial do país diversificou-se, tendo os bens intermediários, de capital e duráveis de consumo crescido mais que os bens não duráveis de consumo. Ao longo das últimas décadas, vêm perdendo importante participação no produto nacional, passando de 39,5\% em 1970 para 34,1\%, em 2002, e 33,9\%, em 2007. (Cano, 2007)

Diversos fatores podem explicar essa queda na participação da região metropolitana de São Paulo, tais como as políticas nacionais para a desconcentração regional e a expansão da fronteira agrícola. Também houve aumento dos custos com aluguel, infraestrutura e dos salários. Em contrapartida, outros territórios passam a oferecer atrativos com economias de aglomeração. (Diniz, 1993)

Logo, a busca por novos espaços produtivos foi delineando-se, e os municípios e estados promovendo ações, a fim de atender às demandas do capital privado. A guerra fiscal foi utilizada para atrair investimentos, e a busca por novos requisitos locacionais, que chegam a uma demanda de qualificação real ou subjetiva dos territórios, levou "as cidades a planejarem suas intervenções urbanísticas a fim de favorecerem os capitais privados, controlando e transformando o espaço em mercadoria seguindo o modelo da rentabilidade. " (Oliveira \& Gomes, 2014)

O estado do Rio de Janeiro, de certa forma, recebeu um impacto da desconcentração de maneira negativa, dada sua dependência do crescimento industrial paulista. Todavia, apesar desse baque na dinâmica regional, "uma ainda acentuada concentração de atividades e a permanência de elementos inegáveis de sua centralidade urbana adiavam uma crise real enquanto o processo de industrialização brasileiro continuasse a lhe impulsionar. " (Sobral, 2007:28)

Muito disso se deve ao fato de que os diversos ciclos econômicos brasileiros deixaram "heranças" para a região do Médio-Paraíba e para o atual estado do Rio de Janeiro. Durante o ciclo do ouro, foram abertas estradas e rotas de conexão com as cidades vizinhas, com a capital do Estado e portos para escoamento das pedras preciosas. Mais adiante, no ciclo cafeeiro, a região começou a tomar os moldes de estruturas urbanas, uma modesta industrialização e uma elite política articulada. Esse legado permitiu a essa região do Sul-Fluminense, embora decadente no início do século XX, passar por uma revitalização e modernização da sua infraestrutura entre 1940 e 1970, o que provocou redução de custos logísticos para a escassa industrialização local. (LIMA, 2005)

Rapidamente a região tornou-se a rota de empreendimentos, em especial do setor automobilístico, que conseguiu atrair para Resende e Porto Real as fábricas de quatro grandes montadoras, e todas, sem exceção, seguem uma agressiva agenda de investimentos: a Volkswagen Caminhões, recentemente adquirida pela MAN Latin America, a sul-coreana Hyundai, a japonesa Nissan - todas essas localizadas em Resende - e a francesa PSA Peugeot Citroën, em Porto Real.

\section{A CHEGADA DA INDÚSTRIA AUTOMOBILÍSTICA E A IDEALIZAÇÃO DE UM "MUNICÍPIO MODELO"}

O município de Porto Real fica localizado ao sul do Rio de Janeiro, Estado com o segundo maior PIB do Brasil, na mesorregião do Sul-Fluminense, no Vale do Paraíba. Pertence à região do Médio-Paraíba, uma das oito Regiões de Governo de acordo com divisão político-administrativa do Estado e tem como municípios limítrofes Barra Mansa, Quatis e Resende. O eixo principal de acesso a Porto Real é a BR-116, a Via Dutra, que alcança Resende a oeste, e Barra Mansa, a sudoeste. As rodovias estaduais, RJ-143 e RJ159, seguem rumo a Nordeste, para Quatis. O município é banhado pelo rio Paraíba do Sul, formado pela união dos rios Paraibuna e Paraitinga, e o seu comprimento, calculado a partir da nascente do Paraitinga, é de mais de $1.100 \mathrm{~km}$. Esse rio serve como divisa, em um grande trecho, entre Resende e Quatis, e que abastece a região.

Apresenta estreita relação com o município de Resende, ao qual pertencia, até 1997, como distrito industrial. A abertura do território onde se localizam Resende, Itatiaia e Porto Real ocorreu em consequência do ciclo do ouro, nos séculos XVII e XVIII, realizada pelos bandeirantes e aventureiros que se interiorizavam em busca das Minas Gerais. A colonização foi iniciada em 1875, quando chegaram ao Brasil, a convite de dom Pedro II, os primeiros imigrantes italianos, de origem católica, que trouxeram para o Brasil a imagem de Nossa Senhora das Dores (Madonna Adolarata), que se tornou padroeira do município. A atividade econômica dominante na época da colonização era a agricultura, tendo como principal produto a 
cana-de-açúcar. Para beneficiar a cana produzida, foi construída uma usina açucareira, a primeira de Porto Real e ponto de partida para sua história industrial.

A colônia continuou crescendo, tornando-se Porto Real o distrito mais importante do município de Resende. Surgiu, então, a pressão por maior autonomia político-administrativa, que deu origem ao movimento próemancipação. Em 5 de outubro de 1995, foi realizado um plebiscito, que decidiu pela emancipação do município, o que se concretizou em face da edição da Lei Estadual no 2.494, de 28 de dezembro de 1995, e instalação em $1^{\circ}$ de janeiro de 1997.

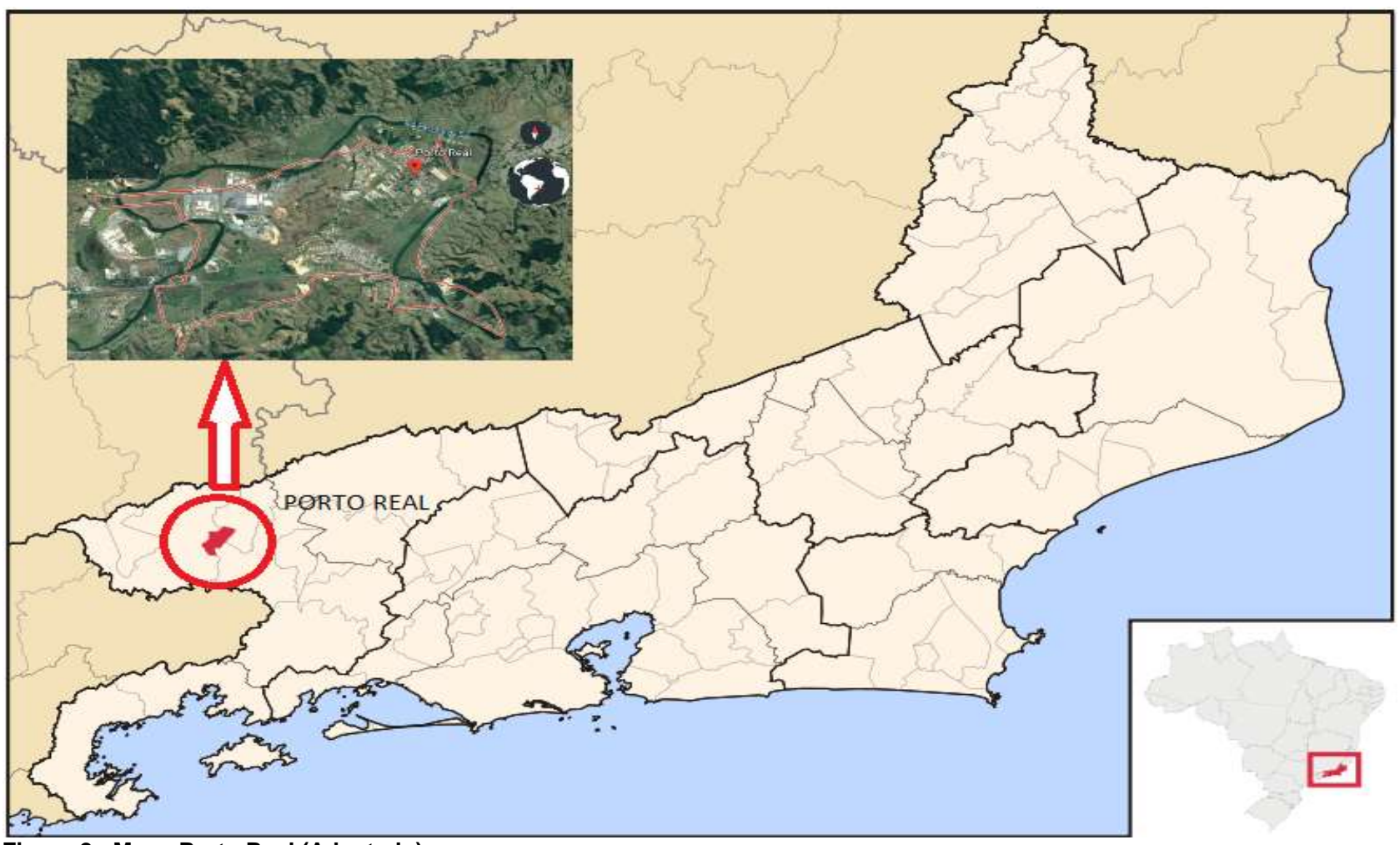

Figura 2 - Mapa Porto Real (Adaptado)

Fonte: https://pt.map-of-rio-de-janeiro.com/munic\%C3\%ADpios-mapas/porto-real-do-mapa

É fato que o empreendimento mais importante para a região do Sul-Fluminense, ainda na primeira metade do século XX, foi a instalação da Companhia Siderúrgica Nacional (CSN) pelo então Presidente Getúlio Vargas como produto das políticas desenvolvimentistas. Conjuntamente, a obra de infraestrutura, ainda desse período, que dinamizou a região do Estado foi a inauguração da rodovia Presidente Dutra, em 1951. Sua construção, ligando Rio de Janeiro a São Paulo, permitiu a Resende uma facilidade de acesso a outros municípios e de escoamento da produção, promovendo uma maior dinamização regional (Dulci, 2015).

Porém, ainda na década de 1970, como um reflexo da desconcentração produtiva, foi criado no município de Resende um distrito industrial com empresas de diversos segmentos, localizado em Porto Real, que até então era um dos distritos do município. O principal fator para a escolha, a princípio, foi por conta de sua localização. Sendo assim, o denominado Polo Urbo-Industrial de Porto Real concentrou grande parte das empresas da região. Isso porque "o debate acerca do desenvolvimento econômico, a nível nacional, tem como marco referencial a observação de uma mudança no paradigma produtivo capitalista, com a necessidade de diversificação, flexibilização e expansão das atividades econômicas, cujos primeiros sinais já se manifestavam no início dos anos setenta" (Paula, 2015:52).

A partir de 1990, o Brasil começou a passar por um processo de abertura econômica e de intensificação da guerra fiscal entre municípios e estados. A região se torna escolhida pela indústria automobilística que passou por uma restruturação, a qual buscava diminuir custos de produção, desenvolver fortes competências para inovação e conquistar novos mercados. Resende conseguiu, assim, atrair duas montadoras: a PSA Peugeot Citroën e a Volkswagen. "(...) em 1994, quando começa a se desenrolar abertamente a "guerra fiscal", o município e a região ensaiam uma recuperação retornando às páginas dos principais jornais do país. O estado do Rio de Janeiro, na época governado por Marcello Alencar (PSDB) e 
a prefeitura de Resende, sob a gestão de Augusto Leivas Nordskog, iniciam uma promissora "conversa" com a Volkswagen, que havia acabado de anunciar a escolha do Brasil como sede da sua fábrica mundial de ônibus e caminhões. " (Lima, 2005:23)

A região apresenta uma série de vantagens locacionais que lhe agregam valor: corredor que liga Rio, São Paulo e Minas Gerais; triângulo que representa entre $70 \%$ e $75 \%$ do mercado consumidor brasileiro; boa infraestrutura (energia, sobretudo gás natural; comunicações, em especial a fibra óptica); malha oeste da Rede Ferroviária Federal S/A- RFFSA; áreas desocupas, planas e drenadas disponíveis à instalação de indústrias e um setor de ensino que não é dos piores (técnico, nível médio e superior). Fator importante também é a proximidade dos principais portos e aeroportos da região Sudeste e do País. No Rio de Janeiro, estão os portos de Sepetiba, Rio de Janeiro e Angra dos Reis, os aeroportos de Resende, Galeão e Santos Dumont. Em São Paulo, o porto de Santos e os aeroportos de Guarulhos e Cumbica.

A escolha por Porto Real, até então distrito de Resende, para receber o grupo PSA PeugeotCitroën, além das vantagens locacionais, levou em consideração uma negociação entre poder público, sociedade civil com determinado poder de influência e a montadora, sempre ponderando aspectos técnicos e políticos. Foi observado que "(...) a oferta de incentivos e privilégios de diversas ordens (isenção do pagamento de impostos, construção de estradas, melhoria dos portos, qualificação da mão de obra, etc) foram utilizados pelas autoridades políticas municipais e estaduais. O diferencial a favor de Resende foi a disponibilidade de uma tradicional empresa local, o Grupo Renato Monteiro, em doar um terreno na ordem de 2 milhões de metros quadrados. " (Lima, 2005:23).

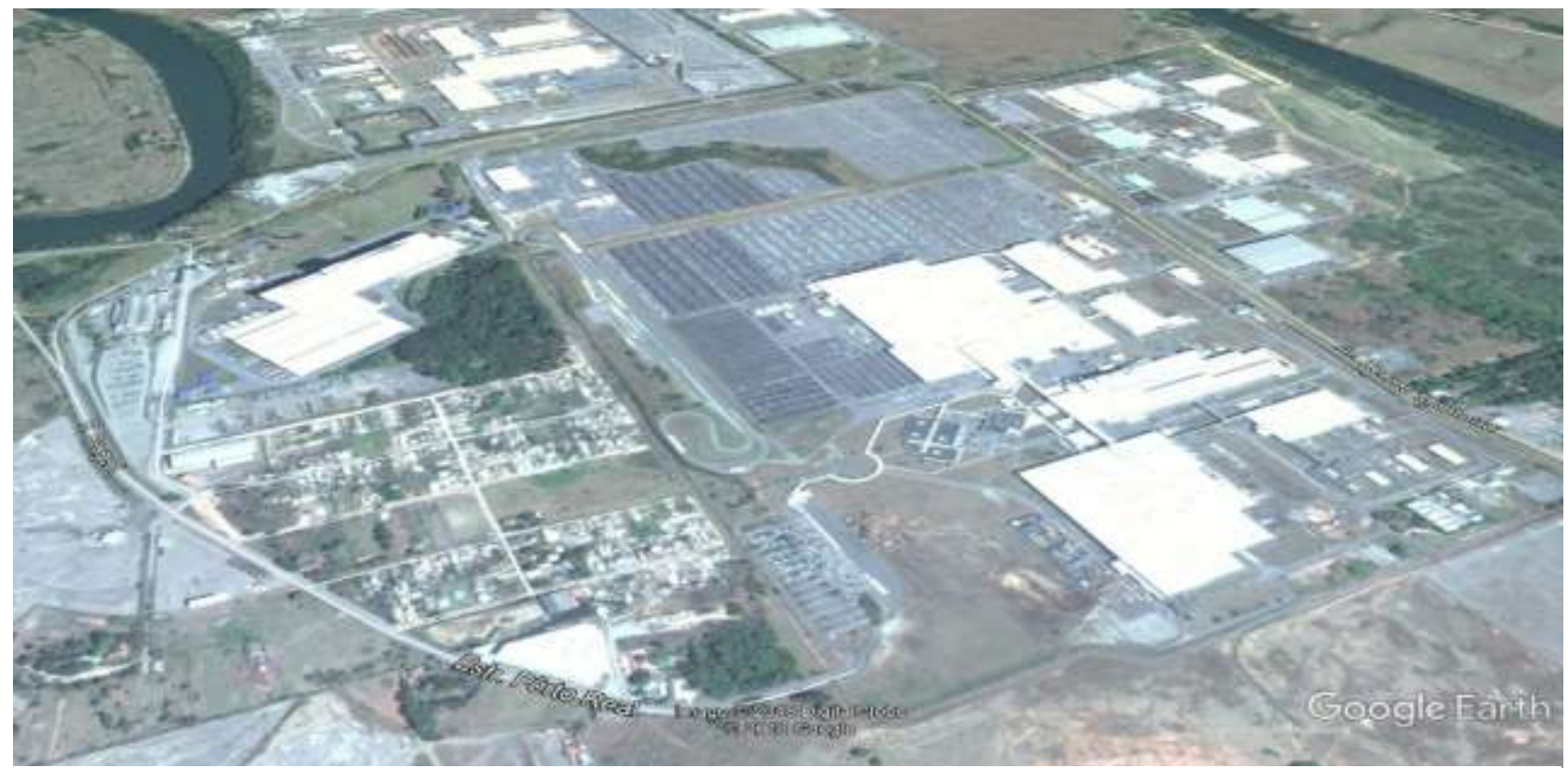

Figura 3 - Imagem de satélite das instalações da PSA Peugeot-Citroën em Porto Real

Fonte: Google Earth

O investimento da PSA Peugeot-Citroën foi da monta de 650 milhões de reais, o maior investimento da montadora fora da França, mas fez com que, segundo Ramalho \& Santana (2006), o estado do Rio de Janeiro arcasse com cerca de $32 \%$ do investimento. Além disso, a montadora fez questão de atrair a sua rede de fornecedores mais próximos, que também se beneficiaram com a doação de terrenos, política implementada por um empresário local como parte de um conjunto de medidas de atração regionais para as novas montadoras. "Isso propiciou a formação de um cinturão de empresas para atender as demandas da produção, acomodados no que foi chamado de "tecnopólo", uma espécie de "distrito industrial" que viabilizava demandas just-in-time. Nesse conjunto estão unidades fabris da Vallourec, que fabrica eixos; da Magnetto-Eurostamp, que se dedica à estamparia de chapa; da Faurecia, fabricante de assentos; e da Gefco, que executa todo o trabalho de logística e transporte da PSA Peugeot Citroën. " (Ramalho \& Santana, 2006:119).

Os indicadores socioeconômicos do município dispararam, com elevação do número de habitantes, Produto Interno Bruto (PIB), da taxa de urbanização e da arrecadação, o que elevou a renda média da população e, 
comisso, alcançando, no ano de 2003, o lugar de município com maior crescimento no estado do Rio de Janeiro. Esse cenário favorável permitiu investimentos da Prefeitura em obras de infraestrutura e de lazer para a população, com o objetivo de passar a imagem de um município moderno. O relatório de acompanhamento brasileiro dos Objetivos de Desenvolvimento do Milênio aponta a evolução dos indicadores de "acesso a água" e "esgoto adequado" em Porto Real, entre 2000 e 2015, a partir de dados publicados pelo IBGE e SNIS. Em 2015, o valor investido pela Prefeitura Municipal de Porto Real, que segundo dados do IBGE tem $99 \%$ de urbanização, em políticas de saneamento urbano foi de R $\$$ 3.522.945,93. (Tribunal de Contas do Estado do Rio de Janeiro, 2000 - 2015)

\section{$5 \quad$ ANÁLISE DE INDICADORES SOCIOECONÔMICOS}

\subsection{Demografia}

Os dados sobre o crescimento populacional apresentados pelo Gráfico 1, mostram o percentual de incremento da população residente em Porto Real em anos selecionados, compreendidos entre $2000 \mathrm{e}$ 2016, relacionando-o com o do estado do Rio de Janeiro, da região do Médio-Paraíba e dos municípios de Resende e Volta Redonda, graças à sua importância econômica.

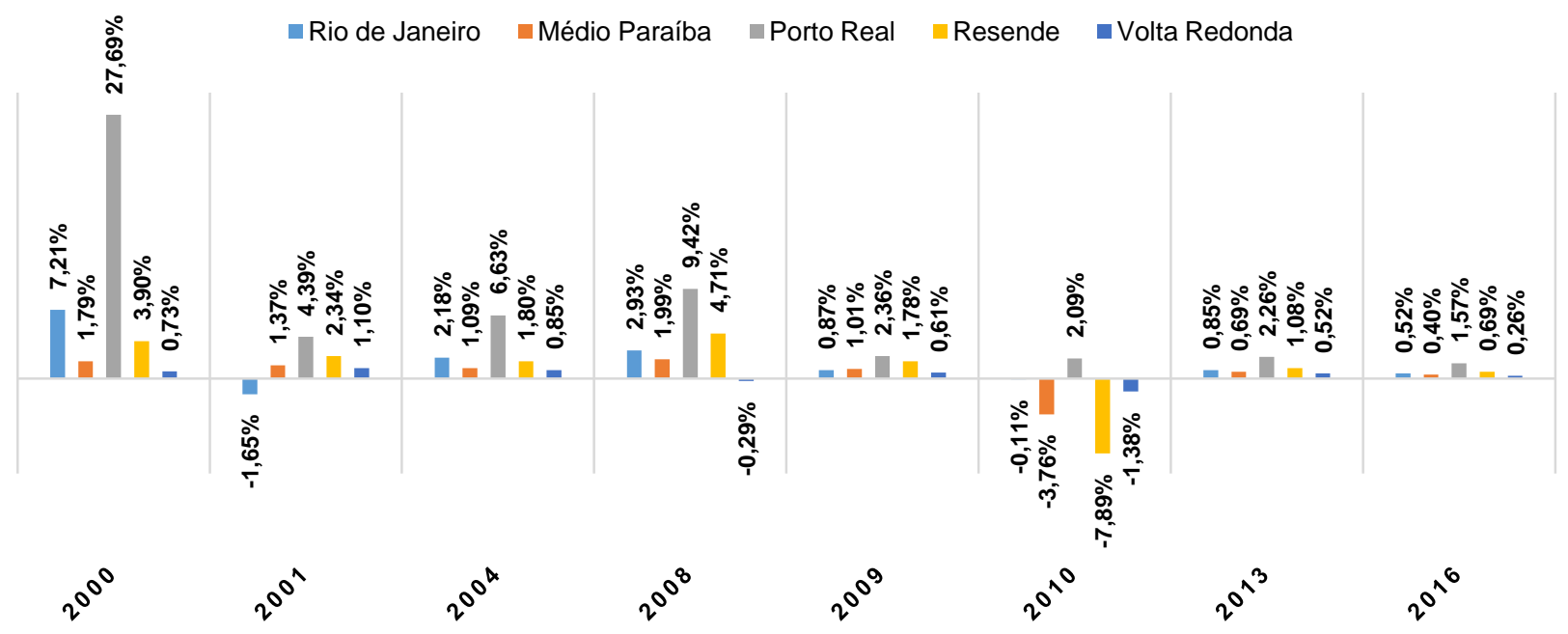

Gráfico 1 - Taxa de crescimento populacional de Porto Real comparada com o estado, divisão estadual administrativa e municípios apurados em anos selecionados

Fonte: DATASUS, IBGE (Elaboração própria)

Porto Real sempre teve uma população muito pequena e com baixa taxa de crescimento. Segundo dados apresentados por Lima (2005:37), em 1940, a população era de 1.014 habitantes, e em 1991, o Censo apontou 8.328 moradores. À época da emancipação do então distrito de Resende, Porto Real tinha um pouco mais de 8.600 moradores e, no Censo de 2000, já eram registrados 12.095 .

As correntes de emigração perderam força e fizeram aumentar a população no Médio-Paraíba. Porém, esse aumento foi discreto se comparado com o município de Porto Real de forma isolada. Os dados do ano de 2000 revelam um crescimento populacional elevado no município. A taxa de $27,69 \%$ de aumento coincide com a chegada das instalações da empresa PSA Peugeot-Citroën. $O$ ano posterior, em que a montadora começou a operar, teve aumento de 4,39\%. O município foi o que mais cresceu na região, com taxas acima de Volta Redonda e Resende e até do próprio Estado, que apresentou uma elevação na taxa populacional, em 2000, e uma queda de 1,65\%, em 2001. A hipótese é de que o aumento populacional está relacionado à demanda por mão de obra para a construção das instalações e funcionários contratados diretamente para a produção e administração da empresa, bem como para as prestadoras de serviços e para as empresas fornecedoras e que pertenciam ao aglomerado empresarial sob o sistema do just-in-time dentro de um tecnopólo, como fábrica de vidro (Guardian), estofados automotivos (Faurencia) e armazenamento (Gefco Lear) (Dulci 2005; Lima, 2005).

Outros picos de crescimento populacional no município de Porto Real destacados foram os dos anos de 2004, com uma elevação de 6,63\%, e em 2008, com 9,42\%. Esses dados estão em conformidade com o 
exposto por Paula (2015), que, com base em entrevista feita com um representante político do município, afirma ter existido uma estratégia das forças políticas locais para ampliação do município e atração de novos moradores, isso porque

Para o município é interessante, aumenta a arrecadação, o município cresce territorialmente, aquece o comercio, gera emprego e renda, aumenta a disponibilidade de mão de obra, atrai instituições de ensino. Para as empresas o fator principal é a redução de custos, com um trabalhador local, a empresa paga menos transporte, diminuem as chances de atrasos ou falta no trabalho, por motivos externos, principalmente para as empresas que trabalham sob o regime de turnos. (Paula, 2015)

Em 2010, de acordo com o Censo, a população foi estimada em 16.592 de residentes, e a projeção para 2017 é de 18.829. Ainda de acordo com o Censo 2010, havia no município 8.242 homens e 8.350 mulheres, com uma população urbana de 16.497 pessoas contra 95 pessoas vivendo na área rural. No mesmo período, houve uma (alta) taxa de urbanização de 99\% e uma densidade demográfica de 326,95 habitantes por $\mathrm{km}^{2}$. De 1998 (quando começou a ser contabilizada) até 2010, a taxa de natalidade decresceu de 21,1
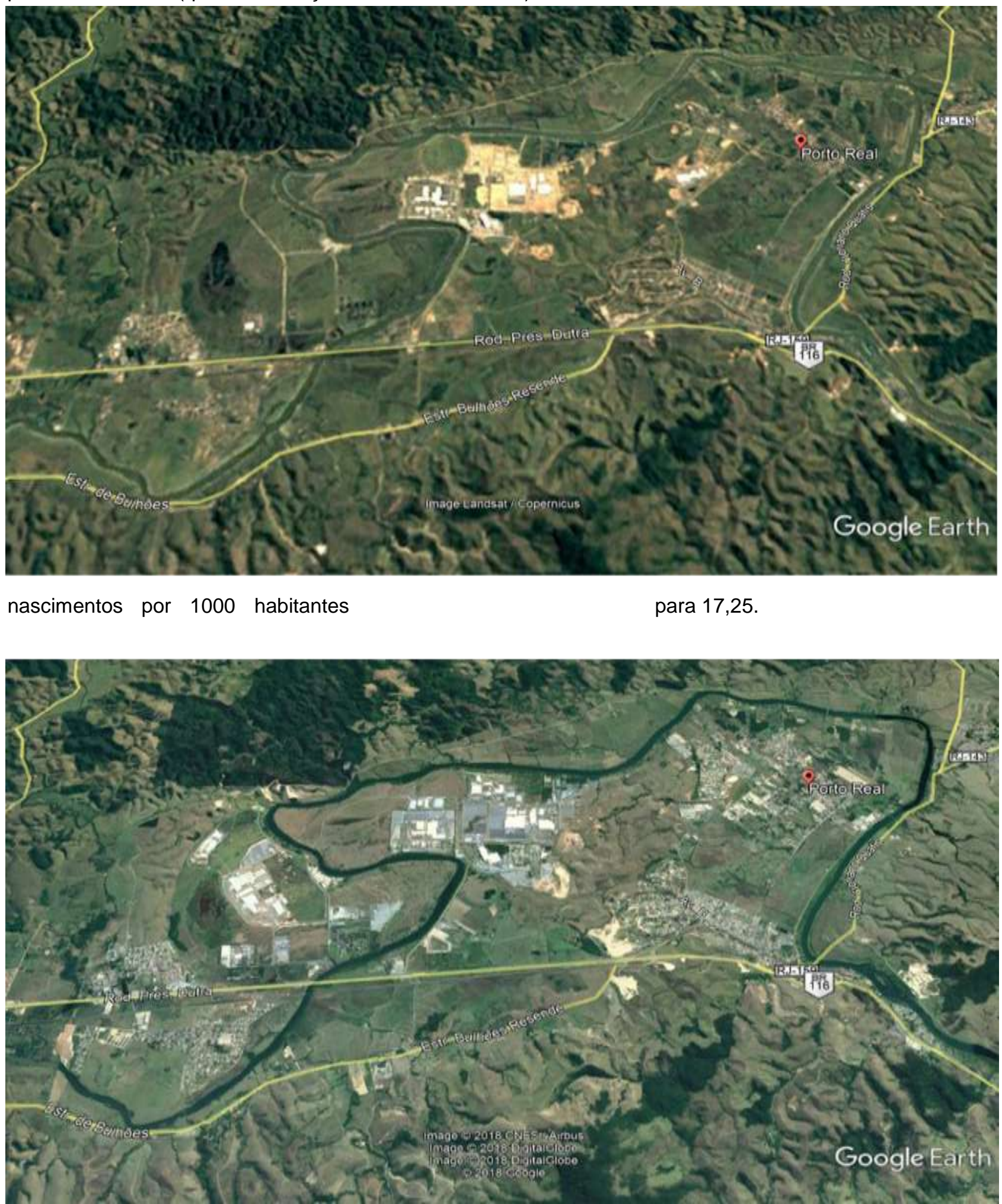
Figura 4 - Imagens de satélite da ocupação espacial de Porto Real nos anos 2000 e 2017 Fonte: Google Earth 


\subsection{Crescimento econômico Municipal, avaliação do PIB e renda}

A chegada da PSA Peugeot-Citroën e a expansão principalmente das indústrias de transformação e de vidro promoveram uma grande inserção de dinheiro na economia do município, fazendo com que o PIB em 2001 fosse $201 \%$ maior que no ano anterior e $322 \%$ maior que em 1999 . O gráfico 2, apresentado abaixo, revela a evolução do PIB de Porto Real entre os anos de 1999 e 2015 e uma comparação com os municípios de Barra Mansa, Resende e Volta Redonda, os maiores PIB's da região.

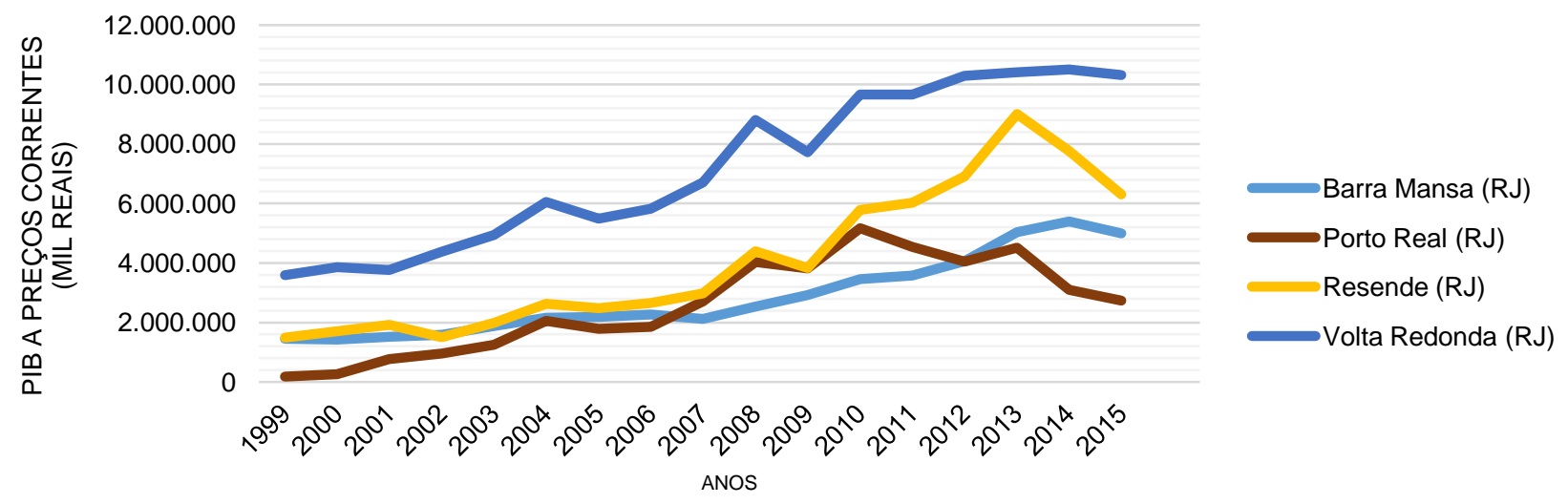

Gráfico 2 - Evolução do PIB de Porto Real em comparação com outros municípios selecionados da região do Médio Paraíba entre os anos 1999-2015

Fonte: Elaboração própria a partir de dados disponibilizados pelo IBGE.

O município viu o principal indicador econômico evoluir ligeiramente até o ano de 2010. Em 1999, o PIB de Porto Real era de $R \$ 182$ milhões. Já em 2001, ano de início da produção da empresa, o PIB foi avaliado em R 769 milhões e, em 2002, calculado em R \$ 952 milhões. Ainda analisando a série histórica, o ápice do Produto Interno Bruto no município foi em 2010, sendo avaliado em $\mathrm{R} \$ 5,18$ bilhões, o que representa um aumento de $572 \%$ desde o início da produção e de $2.735 \%$ em comparação com 1999 . Pode-se observar ainda que, entre 2007 e 2010, os valores do PIB de Porto Real aproximaram-se muito dos de Resende, segundo maior PIB do Médio-Paraíba. Há de se considerar que a população de Resende era, em média de 125 mil habitantes contra 16 mil de Porto Real. Entre 2001 e 2010 a variação média de crescimento do PIB do município foi de $21 \%$.

Logo a proporção do PIB de Porto Real na região tornou-se maior, saindo dos 2,2\% em 1999 e chegando a corresponder a uma parcela de $17,2 \%$ de toda a renda gerada no Médio-Paraíba em 2010, o que fez com que superasse a participação de oito municípios juntos (demais municípios) e, assim, assumiu o terceiro maior PIB da região, porém decaindo para 8\% em 2015.

Esse cenário favorável até 2010 permitiu uma relação entre renda e PIB crescente. Em 1999, a renda per capita do município era de 19,27 mil reais; em 2001, saltou para 61 mil reais; e, em 2010, alcançou a marca de 312 mil reais, um aumento de $411 \%$ desde a inauguração. A quesito de comparação, a tabela apresenta a renda per capita do Brasil, do estado do Rio de Janeiro, dos cinco municípios de maior renda per capita da região do Médio-Paraíba e das cinco maiores rendas da região, bem como a de Porto Real em anos selecionados.

Porém, resultados a partir de 2011 revelam constantes quedas na produção, que acarretaram na queda da participação do município no PIB da região e também da renda. Essa desaceleração na produção tem origem nas crises de 2008 e 2011, que afetaram não só Porto Real, mas também outros municípios do Médio-Paraíba, reduzindo a demanda pelos produtos da indústria automobilística, que é voltada para o mercado externo.

Essas crises causaram turbulência no mercado de automóveis da Europa, afetando diretamente a sede da PSA Peugeot-Citroën na França. O grupo chegou perto da falência no início de 2014, quando anunciou um prejuízo de 2,32 bilhões de euros em 2013, não tendo perspectivas de resultados positivos pelos próximos anos.

Com isso, o resultado bruto do produto gerado em Porto Real sofreu uma acentuada queda, apresentando $\mathrm{R} \$ 4,5$ bilhões em 2011 (uma variação de $-12,15 \%$ com relação a 2010) e de $\mathrm{R} \$ 2,7$ bilhões em 2015 (uma 
variação de $-47,2 \%$ com relação a 2010). Entre 2010 e 2015, a variação média foi de $-10,1 \%$, evidenciando um decrescimento no PIB do município e aumento no desemprego.

Objetivando reverter esse quadro, o governo francês e a montadora chinesa Dongfeng intervieram com uma participação de $14 \%$ em troca de uma injeção de capital. Naquele mesmo ano, a PSA trocou de comando: o português Carlos Tavares, ex-Renault, assumiu o lugar de Philippe Varin na presidência do conselho. O grupo voltou a apresentar um resultado positivo em 2016.

\section{3 Índice de desenvolvimento humano municipal}

Segundo Jannuzzi (2002:60), os indicadores sociais representam medidas quantitativas, dotadas de significado social usado para substituir, quantificar ou operacionalizar um conceito social teórico, isto é, informam algo sobre um aspecto da realidade social ou sobre mudanças que estão ocorrendo na mesma.

Mensurar a qualidade de vida significa avaliar o processo de desenvolvimento, que vai além da simples avaliação do crescimento e da renda per capita. De fato, a questão de se saber o que deve e o que não deve entrar numa avaliação é bastante controversa. Contudo, há um certo consenso quanto à importância de alguns indicadores econômicos e sociais que auxiliam no diagnóstico acerca do estágio de desenvolvimento que são relativos à distribuição de renda, saúde e educação (Paulani \& Braga, 2007).

O IDHM é o mais importante entre eles, pois indica a qualidade de vida a nível municipal. Surgiu em 2012 dos esforços do Programa das Nações Unidas para o Desenvolvimento (PNUD) Brasil, o Instituto de Pesquisa Econômica Aplicada (Ipea) e da Fundação João Pinheiro em adaptar a metodologia do IDH Global para calcular o IDH Municipal. O IDHM brasileiro considera as mesmas três dimensões do IDH Global longevidade, educação e renda.

A Tabela 1 apresenta a evolução do IDHM de Porto Real entre os anos de 2000 e 2010. Os dados são elaborados com base nos censos que ocorrem de dez em dez anos. Pode-se observar que o IDHM foi de 0,713, em 2010, colocando Porto Real na faixa de Desenvolvimento Humano Alto ${ }^{2}$. A dimensão que mais contribuiu foi a longevidade, com índice de 0,817, seguida de renda, com índice de 0,688, e de educação, com índice de 0,645.

\begin{tabular}{ccc} 
Anos & $\mathbf{2 0 0 0}$ & $\mathbf{2 0 1 0}$ \\
\hline IDHM & $\mathbf{0 , 5 6 8}$ & $\mathbf{0 , 7 1 3}$ \\
IDHM Educação & 0,393 & 0,645 \\
IDHM Longevidade & 0,726 & 0,817 \\
IDHM Renda & 0,643 & 0,688 \\
\hline
\end{tabular}

Tabela 1 - Índice de Desenvolvimento Humano Municipal e seus componentes - Município - Porto Real - RJ Fonte: Atlas Brasil

O IDHM passou de 0,568 , em 2000, para 0,713 , em 2010, o que representa uma taxa de crescimento de 25,53\%. Nesses mesmos anos, o IDHM do Brasil foi de 0,612, em 2000, e de 0,727, em 2010; já o do estado do Rio de Janeiro foi de 0,664, em 2000, e de 0,761, em 2010. O hiato de desenvolvimento humano, ou seja, a distância entre o IDHM do município e o limite máximo do índice, que é 1, foi reduzido em $66,44 \%$ entre 2000 e 2010. Nesse período, a dimensão cujo índice mais cresceu em termos absolutos foi Educação (com crescimento de 0,252), seguida por Longevidade e por Renda. Porto Real ocupa a 1514a posição entre os 5.565 municípios brasileiros segundo o IDHM. (Atlas Brasil, 2018)

\subsection{Mercado de trabalho}

Fazia parte das estratégias das empresas que buscavam o Brasil na década de 1990 para se instalarem e como potencial mercado consumidor contratar uma força de trabalho jovem e inexperiente. Inclusive, a escolha da PSA Peugeot-Citroën por Porto Real foi a escolha de uma mão de obra que não tivesse contato anteriormente com a indústria automobilística de setores mais tradicionais, como a região do $A B C$ Paulista ${ }^{3}$, em São Paulo. Somou-se a isso a contratação de trabalhadores, de preferência locais, com um padrão mais elevado de escolarização - a partir do Ensino Médio - e que foram qualificados conforme os interesses da

\footnotetext{
${ }^{2}$ IDHM entre 0,700 e 0,799

${ }^{3}$ Região do estado de São Paulo onde, tradicionalmente, se concentrava a indústria automobilística.
} 
PSA Peugeot-Citroën. "Em todo o processo de instalação da montadora, a participação do Senai ${ }^{4}$ foi fundamental como agente intermediário (...) A empresa buscou uma associação rápida e estreita com esse centro de formação de profissionais, não só o equipando com instrumental para cursos ligados às demandas da indústria automobilística, mas também oferecendo cursos e convênios. (...) A montadora construiu um protótipo da linha de montagem dentro do Senai, para que os alunos se adequassem às especificidades técnicas da nova planta (...) incluiu até mesmo os próprios técnicos do Senai, que não só tiveram que readaptar as instalações físicas, como também receber instruções no exterior" (Ramalho \& Santana, 2006:120).

Diferentemente das expectativas sobre as novas oportunidades de emprego que as empresas recémchegadas ofereceriam, as coisas não aconteceram como se imaginava. Acreditava-se que a PSA PeugeotCitroën fosse gerar em torno de 16 mil empregos, entre diretos e indiretos, juntamente com suas fornecedoras de autopeças.

Dados disponibilizados pela Relação Anual de Informações Sociais (RAIS) mostram que o município, em 2016, contava com um estabelecimento para a fabricação de automóveis, camionetas e utilitários, um para fabricação de caminhões e ônibus e dez para fabricação de peças e acessórios para veículos automotores e empregava, nesse mesmo ano, 3.449 pessoas, com remuneração média de $R \$ 3.613$. Desses, 2.184 trabalhadores estavam empregados na PSA Peugeot-Citroën com remuneração média de $R \$ 4.087,44$.

O sindicato institui-se mais enfraquecido e menos atuante, e como consequência reduziram-se os custos de mão de obra, pagando salários mais baixos. Assim como proposto por Ramalho (2006), apresenta-se uma comparação com a região do $A B C$ Paulista, a qual apresenta um sindicato mais coeso e fortalecido. No ano de 2016, a remuneração média para o setor em Porto Real e Resende foi de $R \$ 2.541$. Já para os municípios de São Bernardo do Campo e São Caetano do Sul, o salário médio é de $\mathrm{R} \$ 7.385$, uma variação de $191 \%$ nos salários. No que diz respeito à aquisição de uma cesta de produtos e serviços, segundo o Departamento Intersindical de Estatística e Estudos Socioeconômicos, o argumento de que as diferenças nos itens compensariam a diferença não se confirma. Em Porto Real e Resende, os gastos com alimentação, habitação, equipamentos domésticos, transporte, vestuário, educação, saúde, recreação e despesas pessoais são de $R \$ 3.854,63$ contra $R \$ 4.402,51$ de gastos em São Bernardo do Campo e São Caetano do Sul (dados disponíveis para 2002 e corrigidos pelo autor pelo IPCA - IBGE)

\subsection{Tributos e receitas}

Ao analisar o desempenho econômico financeiro do município com dados fornecidos pelas prestações de contas de administração financeira encaminhada ao Tribunal de Contas do Estado do Rio de Janeiro (TCERJ), podemos fazer algumas observações sobre os impactos das isenções fiscais e do recolhimento dos impostos sobre a produção industrial em Porto Real. Foram selecionados indicadores sobre o equilíbrio orçamentário, a autonomia financeira do município e o seu grau de dependência de transferência de recursos do Estado e apresentados na Tabela 2.

\begin{tabular}{cccc} 
Anos & $\begin{array}{c}\text { Equilíbrio } \\
\text { orçamentário }^{5}\end{array}$ & $\begin{array}{c}\text { Autonomia } \\
\text { Financeira }^{6}\end{array}$ & $\begin{array}{c}\text { Dependência } \\
\text { Financeira }^{7}\end{array}$ \\
\hline $\mathbf{2 0 0 0}$ & 0,9735 & 0,27 & 0,74 \\
$\mathbf{2 0 0 1}$ & 0,9608 & 0,15 & 0,83 \\
$\mathbf{2 0 0 2}$ & 0,8726 & 0,102 & 0,87 \\
$\mathbf{2 0 0 3}$ & 0,9511 & 0,098 & 0,86 \\
$\mathbf{2 0 0 4}$ & 0,9904 & 0,073 & 0,89 \\
$\mathbf{2 0 0 5}$ & 1,0229 & 0,059 & 0,88 \\
$\mathbf{2 0 0 6}$ & 0,9835 & 0,066 & 0,87 \\
$\mathbf{2 0 0 7}$ & 0,9994 & 0,072 & 0,81 \\
$\mathbf{2 0 0 9}$ & 0,9449 & 0,068 & 0,83 \\
$\mathbf{2 0 1 0}$ & 1,0087 & 0,064 & 0,84 \\
$\mathbf{2 0 1 1}$ & 1,0208 & 0,082 & 0,83
\end{tabular}

\footnotetext{
${ }^{4}$ Serviço Nacional de Aprendizagem Industrial

${ }^{5}$ Razão entre receita realizada e despesa executada

${ }^{6}$ Razão entre receita tributária própria e despesas de custeio

${ }^{7}$ Razão entre transferências correntes e de capital e receita realizada
} 


\begin{tabular}{rccc}
$\mathbf{2 0 1 2}$ & 0,933 & 0,074 & 0,81 \\
$\mathbf{2 0 1 3}$ & 1,0232 & 0,08 & 0,83 \\
$\mathbf{2 0 1 4}$ & 0,8557 & 0,086 & 0,8 \\
$\mathbf{2 0 1 5}$ & 0,8826 & 0,166 & 0,82 \\
\hline
\end{tabular}

Tabela 2 - Análise de alguns indicadores financeiros

Fonte: TCE - RJ

Podemos interpretar o equilíbrio orçamentário como o quanto da receita realizada consegue arcar com a despesa executada, em que resultados maiores do que um expressam situação de superávit, e os inferiores, déficit. No ano 2000, para cada $R \$ 100$ gastos pela Administração Pública, o município arrecadava $R \$ 97,35$. Nos quinze anos analisados, em apenas quatro foi verificado equilíbrio econômico.

Quanto à autonomia financeira do município, procura-se investigar o quanto da contribuição da receita tributária própria do município atende às despesas com a manutenção dos serviços da máquina administrativa. Em 2000, a autonomia financeira era de 27\% e apresentou sucessivas quedas até atingir 5,9\%, o menor índice verificado no período analisado. Em 2015 esse índice foi de 16,6\%, dado um aumento significativo nas receitas tributárias e queda nas despesas correntes. Como consequência, a dependência financeira por transferências vindas do Estado aumentou de 74\% em 2000, para 82\% em 2015. A dependência de transferências da União, do Estado e dos royalties do petróleo governamentais (royalties, royalties excedentes e participações especiais) atingiu $92 \%$ e o município de Porto Real tem nelas $5 \%$ de sua receita total. (Tribunal de Contas do Estado do Rio de Janeiro, 2000 - 2015)

Ao analisarmos o grau de investimento e desenvolvimento local proposto pelos estudos socioeconômicos desenvolvidos pelo TCE - RJ, observamos que, entre 2010 e 2015, o nível de investimento per capita caiu de $R \$ 947,03$, em 2010 , para $R \$ 231,08$ por habitante. Se confrontarmos os investimentos com a receita arrecadada, em 2010 , os investimentos representavam $11,94 \%$ da receita, e em 2015 , apenas $2,5 \%$.

Segundo o TCE-RJ, constatou-se a tendência dos governos locais de direcionarem as participações governamentais para manutenção das atividades da administração municipal em detrimento dos investimentos. É possível salientar, ainda, a falta de planejamento e implementação de políticas públicas locais consistentes, de infraestrutura para grandes empreendimentos e de ações que fomentem a transparência na prestação de contas da administração pública para com os contribuintes e o planejamento participativo. (Tribunal de Contas do Estado do Rio de Janeiro, 2000 - 2015)

\section{CONSIDERAÇÕES FINAIS}

Para compreendermos de que forma o processo de desconcentração produtiva promoveu uma dinamização na região sul do Rio de Janeiro, em especial no município de Porto Real, precisamos entender de que forma os fenômenos de concentração e desconcentração se configuraram e como as principais regiões envolvidas no processo estão interligadas historicamente. Iniciadas no Rio de Janeiro por volta de 1820 , as fazendas produtoras de café logo se expandiram ao longo do vale do Rio Paraíba do Sul com grandes propriedades que se estendiam por Vassouras, Resende, Barra Mansa, Valença. Porém, a partir de 1870, começa-se a observar uma "marcha para o oeste" paulista, que foi tornando-se a área mais dinâmica da economia brasileira, com o surgimento de novas indústrias que circundavam o complexo cafeeiro, distanciando-se cada vez mais em produtividade da então declinante região do Vale do Paraíba e tornando-se cada vez mais concentrada em São Paulo. A partir de 1920 que as disparidades com o resto do país passaram a ser mais evidentes, considerando-se o processo concentrador. Os Censos industriais mostram que, em 1907, a porcentagem do valor bruto da produção industrial de São Paulo em relação ao total do Brasil era de 15,9\%. Em 1919, a concentração industrial no Estado era de 31,5\% e, em 1939, essa participação era de 45,4\%. A economia baseada no complexo cafeeiro teve grande contribuição durante o processo de concentração, que começou a reverter-se em 1970.

Não se deve deixar de salientar a importância do estado do Rio de Janeiro e da região do Vale do Paraíba para a economia fluminense e brasileira. Ainda que não tendo acompanhado São Paulo de forma paralela durante o processo de industrialização, o estado do Rio de Janeiro detém a segunda maior participação no produto nacional do Brasil, foi capital do Brasil de 1621 até 1960, palco de acontecimentos históricos e detém a sede e representações de importantes bancos e empresas nacionais e internacionais, como a Petrobrás, Banco Nacional de Desenvolvimento Econômico e Social (BNDES), a Companhia Siderúrgica Nacional (CSN) em Volta Redonda, a PSA Peugeot-Citroën em Porto Real, dentre outras. 
Porto Real desperta interesse no que condiz à temática do desenvolvimento regional porque, em oito anos após sua fundação, já reunia indústrias de peso (com destaque para a montadora PSA Peugeot-Citroën), que respondem pelo aumento recorde do seu PIB. Partindo do pressuposto de que o município é um caso ainda em execução de engenharia social, onde o seu crescimento vem resultando de uma fusão preexistente entre público e privado, objetivou-se apresentar a sua formação como um fenômeno envolvido na articulação de uma rede bem específica de relações sociais.

O município foi reconfigurado para receber a PSA Peugeot-Citroën, modificando sua dinâmica e paisagem e promovendo diversas intervenções urbanísticas de infraestrutura, bem como criando novos usos para o espaço, a fim de transformar a imagem de uma pacata cidade do interior do Rio de Janeiro em uma cidade moderna e com valorização da terra.

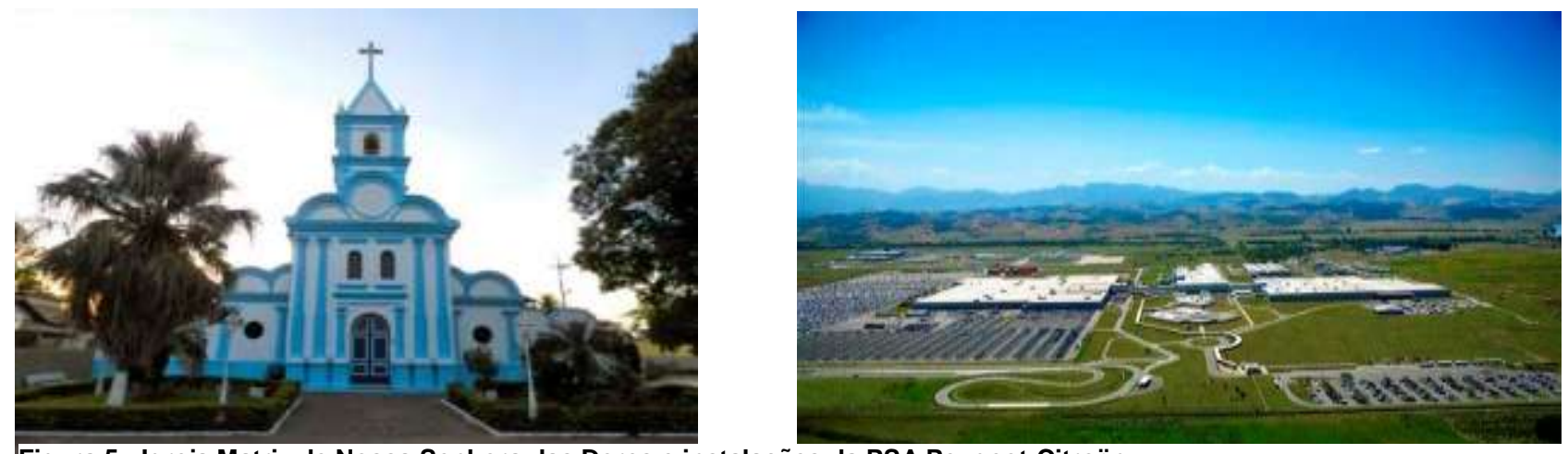

Figura 5 - Igreja Matriz de Nossa Senhora das Dores e instalações da PSA Peugeot-Citroën

Fontes: http://www.turismovaledocafe.com/2014/09/porto-real-rj.html

http://motordream.uol.com.br/noticias/ver/2011/04/16/psa-1-milhao-de-motores-em-porto-real

Para dar conta das exigências da montadora francesa, procurou atrair mão de obra com a promessa de muitas vagas de emprego e salários atrativos, o que acabou não se realizando. Também contou com o auxílio do Estado com a instalação da UERJ, e beneficiou-se com a chegada do CEDERJ ao município de Resende, o que elevou significativamente o IDHM da educação no município.

Essa análise inicial possibilitou constatar que Porto Real apresenta índices socioeconômicos muito animadores e em níveis elevados. Porém, as isenções fiscais se mostraram, de certa forma, prejudicial para o município, tornando-o mais dependente de repasses. A utilização contínua desses recursos em despesas correntes não gera investimentos diretos, logo os investimentos públicos não conseguiram se sustentar ao longo do tempo. Também foi possível constatar que os salários pagos nessa nova localidade foram estabelecidos em um nível menor do que na região do ABC Paulista e que o custo de vida não explica tal diferença. Com isso, pode-se concluir que a escolha de Porto Real para a instalação da montadora levou em consideração a redução de custos via salário.

\section{6 \\ BIBLIOGRAFIA}

Baer, W. (2003). A Economia Brasileira. Nobel.

Cano, W. (1998). Raízes da Concentração Industrial em São Paulo. Campinas: UNICAMP - Instituto de Economia.

(2007). Desconcentração produtiva regional do Brasil: 1970-2005. São Paulo: UNESP.

Diniz, C. C. (1993). Desenvolvimento poligonal no Brasil: nem desconcentração, nem contínua polarização. Nova Economia, 35-64.

Jannuzzi, P. d. (2002). Considerações sobre o uso, mau uso e abuso dos indicadores sociais na formulação e avaliação de políticas públicas municipais. RAP, 51-72.

Lima, R. J. (2005). Açúcar, Coca-Cola e Automóveis: Ação Político-Empresarial na Construção de um "Município Modelo" em Porto Real (RJ). Dissertação. Rio de Janeiro, RJ, Brasil: UFRJ. 
Marco Aurélio dos Santos, B. A. (2017). A formação da economia cafeeira do vale do Paraíba. Topoi, 196201.

Oliveira, J. C., \& Gomes, N. H. (2014). Intervenções urbanísticas, mudanças na paisagem e homogeneização do espaço: Análise dos bairros Andorinhas e Santa Martha, Vitória - ES. VII Congresso Brasileiro de Geógrafos. Vitória.

Pacheco, C. A. (junho de 1996). Desconcentração econômica e fragmentaçãoda economia nacional. Economia e Sociedade, pp. 113-140.

Paula, E. K. (2015). PÓLO AUTOMOTIVO SUL FLUMINENSE: novos rumos para o desenvolvimento econômico da região. Dissertação (Mestrado). Rio de Janeiro, Rio de Janeiro, Brasil.

Paulani, L. M., \& Braga, M. B. (2007). A nova contabilidade social. São Paulo: Saraiva.

Ramalho, J. R., \& Santana, M. A. (2006). Flexibilidade à francesa: trabalhadores na Peugeot Citroën brasileira. Tempo Social, 115-132.

Schmidt, M. (2008). Nova História Crítica. São Paulo: Nova Geração.

Sobral, B. L. (2007). Desconcentração Produtiva Regional no Brasil. Dissertação (Mestrado). Campinas, São Paulo, Brasil.

Sobrinho, A. M. (1978). A civilização do café (1820-1920). São Paulo: Brasiliense.

Tribunal de Contas do Estado do Rio de Janeiro. (2000 - 2015). Estudos Socieconômicos. Rio de Janeiro: Secretaria Geral de Planejamento.

\section{Fuentes electrónicas:}

Fundação CEPERJ: http://www.ceperj.rj.gov.br/ceep/info_territorios/divis_regional.html (Consulta: 20/11/ 2017).

IBGE: https://cidades.ibge.gov.br/xtras/perfil.php?lang=\&codmun=3304110 (Consulta: 20/11/2017).

Ministério do Trabalho e Emprego - PDET (RAIS e CAGED): http://bi.mte.gov.br/bgcaged/rais.php. (Consulta: 16/02/2018).

http://www.turismovaledocafe.com/2014/09/porto-real-rj.html (Consulta: 28/02/2018).

http://motordream.uol.com.br/noticias/ver/2011/04/16/psa-1-milhao-de-motores-em-porto-real (Consulta: 28/02/2018). 